\title{
Ciprofloxacin conjugated zinc oxide nanoparticle: A camouflage towards multidrug resistant bacteria
}

\author{
PRASUN PATRA ${ }^{\mathrm{a}, *}$, SHOUVIK MITRA ${ }^{\mathrm{a}}$, NITAI DEBNATH ${ }^{\mathrm{a}}$, PANCHANAN PRAMANIK $^{\mathrm{b}}$ and \\ ARUNAVA GOSWAMI ${ }^{\mathrm{a}}$ \\ ${ }^{a}$ AERU, Biological Sciences Division, Indian Statistical Institute, Kolkata 700 108, India \\ ${ }^{b}$ Department of Chemistry, Indian Institute of Technology, Kharagpur, Kharagpur 721 302, India
}

MS received 23 March 2012; revised 1 October 2012

\begin{abstract}
Gradual development of antibiotic resistant bacteria is producing severe global threat. Newer strategies are now being employed in order to control the microbial infections and to reduce the mortality as well as infection rates. Herein we describe successful synthesis of $\mathrm{ZnO}$ nanoparticles (ZNP) under microwave assisted condition followed by functionalization with ciprofloxacin, an antibiotic, using EDC/NHS chemistry. Successful conjugation of ciprofloxacin was confirmed by FTIR spectra. Ciprofloxacin-conjugated ZnO nanoparticles (ZN-CIP) exhibited excellent antibacterial activity against clinically isolated multidrug resistant bacterial strains of Escherichia coli, Staphylococcus aureus and Klebsiella sp. ZNP were small in size with particle size distribution 18-20 $\mathbf{~ m}$ as obtained from transmission electron microscope (TEM). Surface topology was obtained from atomic force microscopic (AFM) image and $x$-ray diffraction confirmed that ZNP possessed hexagonal crystal structure. A concentration of $10 \mu \mathrm{g} / \mathrm{mL}$ of $\mathrm{ZN}$-CIP was a benchmark concentration. During evaluation of minimum inhibitory concentration (MIC) values, similar concentration of antibiotic was incapable of producing antibacterial activity.
\end{abstract}

Keywords. Zinc oxide nanoparticles; ciprofloxacin; chemical conjugation; antibacterial property.

\section{Introduction}

Gradual development of antibiotic resistant bacteria is producing severe global threat. Pathogenic species of Escherichia coli, Staphylococcus aureus and Klebsiella sp. are the common examples of such bacteria that cause a variety of infectious diseases worldwide. Recently in 2011, many people died in Germany due to severe infection caused by E. coli (BBC News, 1 June 2011) Staphylococcus is very well known for wide spectrum of phylogenic infections (Blanc et al 2000); meanwhile Klebsiella sp. can lead to a wide range of disease states, notably pneumonia, urinary tract infections, septicemia, ankylotic spondylitis and soft tissue infections. Newer strategies are now being employed in order to control the microbial infections and to reduce the mortality as well as infection rates (Saha et al 2007; Turos et al 2007; Chakraborty et al 2010). Rapid advance in nanotechnology offers researchers to apply diverse nanomaterials against biocidal applications. Nanoparticles of $\mathrm{TiO}_{2}, \mathrm{ZnO}$, silver, etc. are commonly known for their biocidal efficacy. $\mathrm{ZnO}$ is one of the five compounds identified as GRAS (generally recognized as safe) by US food and drug administration (Mitra et al 2012). Therefore, in this study we have exploited a safe nanomaterial fabricated with antibiotic towards antibiotic resistant bacteria to minimize the infectious effect.

$\mathrm{ZnO}$ nanoparticle (ZNP), with its versatile potential and multifunctional application, has grown to be one of the most promising nanomaterials. ZNP, with its band gap of $3.37 \mathrm{eV}$ and a large excitation binding energy of $60 \mathrm{meV}$, can exhibit near ultraviolet emission and transparent conductivity. Wide applications of ZNP includes its use in cosmetics, medicine and drug delivery. ZNP is widely used in biosensors (Ren et al 2009), electrodes ( $\mathrm{Ku}$ and $\mathrm{Wu} 2007$ ), biogenerators (Wang and Song 2006), solar cells (Lee et al 2008), acoustic devices (Chivukula et al 2010), luminescent devices (Yude et al 2006) and in catalysis (Li et al 2009). Recently numerous works have been done on antimicrobial activity especially onantibacterial activity (Reddy et al 2007; Padmavathy and Vijayaraghavan 2008). Antibacterial activity of $\mathrm{ZnO}$ doped in silica matrix was observed against E. coli (Dutta et al 2010). Applerot et al (2009) proposed that formation of reactive oxygen species was the formal mechanism behind the damage of microbial system. Ciprofloxacin is one of the most significant antibiotics used in medicinal sector. Therefore, conjugation of antibiotic with a nanoparticle is expected to increase its efficacy. We have chosen ZNP to conjugate with antibiotic as $\mathrm{ZnO}$, which is biosafe and biocompatible and can be used for biomedical application without coating (Wang 2004). Banoee et al (2010) have reported that mixture of zinc oxide and ciprofloxacin is effective against bacterial system. However, no reports are still available on antibacterial activity of chemically conjugated ciprofloxacin against multidrug resistant bacteria to best of our knowledge.

Herein we describe successful synthesis of ZNP under microwave assisted condition followed by fabrication of ZNP with an antibiotic ciprofloxacin. ZNP was then amine

*Author for correspondence (bioprasun@gmail.com) 
functionalized by using a silane coupling agent APTES (3aminopropyltriethoxysilane) under refluxing condition using dimethyl sulphoxide as the solvent. Ciprofloxacin was then conjugated with ZNP using EDC/NHS chemistry to produce ciprofloxacin conjugated zinc oxide nanoparticle (ZN-CIP). Successful chemical conjugation was confirmed by UVVis and FTIR spectra. ZN-CIP exhibited brilliant antibacterial activity against clinically isolated multidrug resistant bacteria with dose dependency.

\section{Experimental}

\subsection{Materials}

Zinc acetate dihydrate, tris(hydroxymethyl)aminomethane, dimethyl sulfoxide, ethanol and 3-ethyldimethylaminopropyl carbodiimide (EDC) were purchased from Merck (India), N-hydroxysuccinimide (NHS) was purchased from SRL (India), 3-aminopropyltriethoxysilane was purchased from Sigma Aldrich and Muller Hilton broth was obtained from Himedia. All the chemicals were of analytical grade and used without further purification. Milli-Q grade water (Sartorious Stedim Biotech) was used throughout the experiment with conductivity less than $0 \cdot 1 \mu \mathrm{S} \mathrm{cm}^{-1}$.

\subsection{Synthesis of $\mathrm{ZnO}$ nanoparticle}

Most of the reported methods involve synthesis of zinc oxide under strong alkaline and drastic conditions. But, we have used TRIS buffer providing milder conditions. In brief, $20 \mathrm{ml}$ $20 \%$ aqueous TRIS solution was added drop wise to $25 \mathrm{ml}$ of $0.05(\mathrm{M})$ zinc acetate dihydrate solution. The mixture was stirred well and then subjected to microwave irradiation at 300 watt for $3 \mathrm{~min}$ in a domestic microwave. The obtained product was centrifuged at $10000 \mathrm{rpm}$ for $10 \mathrm{~min}$ and washed several times with milli-Q water in order to remove excess of TRIS buffer. Finally, the product was washed with ethanol and dried overnight at $80^{\circ} \mathrm{C}$ in a hot air oven.

\subsection{Amine functionalization of $\mathrm{ZnO}$ nanoparticle}

Amine functionalization of ZNP was carried out by using 3-aminopropyltriethoxysilane via co-condensation reaction with modification of the reported method (Guo et al 2009). In brief, about $0.5 \mathrm{~g}$ of ZNP was dispersed in about $50 \mathrm{~mL}$ of DMSO in a sonication bath for about $1 \mathrm{~h}$. The resultant dispersion was transferred to a round bottom flask attached with a reflux condenser. To it $400 \mu \mathrm{L}$ of 3-APTES was added and the solution was refluxed at $120^{\circ} \mathrm{C}$ for about $3 \mathrm{~h}$. After completion of the reaction, the resulting nanoparticle was centrifuged at $12000 \mathrm{rpm}$ for about $15 \mathrm{~min}$ and washed several times with ethanol to remove the unreacted 3-APTES. Finally, the product was dried at $60{ }^{\circ} \mathrm{C}$ overnight to produce amine functionalized ZNP.

\subsection{Conjugation of ciprofloxacin with $\mathrm{ZnO}$ nanoparticles}

Ciprofloxacin was chemically conjugated with amine functionalized ZNP using EDC/NHS chemistry. Briefly, $15 \mathrm{mg}$ of ciprofloxacin was dispersed by sonication in $30 \mathrm{~mL} \mathrm{1:1}$ aqueous DMSO. To it, $8 \mathrm{mg}$ of EDC was added followed by the addition of $8 \mathrm{mg}$ of NHS. pH of the system was maintained at 6 . The mixture was allowed to stir for $3 \mathrm{~h}$ in a dark atmosphere. After activation of ciprofloxacin, $30 \mathrm{mg}$ of amine functionalized $\mathrm{ZNP}$ dispersed in $10 \mathrm{~mL}$ of $1: 1$ aqueous DMSO was added dropwise. $\mathrm{pH}$ was maintained at 8 and the reaction mixture was allowed to stir overnight. Then, $\mathrm{ZN}-$ CIP was obtained by centrifugation of the reaction mixture at $4000 \mathrm{rpm}$ for about $15 \mathrm{~min}$ and washed a few times with DMSO and ethanol. Finally obtained ZN-CIP was dried at $60{ }^{\circ} \mathrm{C}$.

\subsection{Antibacterial assay}

Multi drug resistant (resistant to ciprofloxacin, ofloxacine, tetracycline, chloramphenicol and gintamicin) pathogenic bacterial strains of E. coli, Staphylococcus aureus and Klebseilla sp. were isolated from clinical specimens (urine, throat swab and pus) which were grown in Muller Hilton broth medium at $37{ }^{\circ} \mathrm{C}$ temperature under aerobic conditions. Strains were routinely cultured overnight at $37{ }^{\circ} \mathrm{C}$ with agitation in $\mathrm{MH}$ broth. At experimental phase, bacteria were harvested by centrifugation at $3000 \mathrm{rpm}$ for $10 \mathrm{~min}$ and washed twice with phosphate buffer saline (PBS, pH 7.2) and then resuspended in PBS. The bacterial concentration was adjusted to $1 \times 10^{6} \mathrm{CFU} / \mathrm{mL}$ by using the optical density (OD) of bacterial suspension.

Then $50 \mu \mathrm{L}$ of inocula $\left(1 \times 10^{6} \mathrm{CFU} / \mathrm{mL}\right)$ were added to $5 \mathrm{~mL}$ of Muller Hilton broth followed by addition of $\mathrm{ZN}$ CIP dispersions of concentration of 1, 2, 5, 10, 20, 40, 60, $80,160,320,500$ and $1000 \mu \mathrm{g} / \mathrm{mL}$ with respect to total volume of $5 \mathrm{~mL}$. Finally, autoclaved deionized water was added to make up the volume $5 \mathrm{~mL}$ of each test tube. The dispersions were cultured at $37{ }^{\circ} \mathrm{C}$ with gentle stirring. In liquid medium, the growth of bacterial strains was indexed by measuring OD at $600 \mathrm{~nm}$ against abiotic control using UV-Vis spectrophotometer (Dutta et al 2010).

\subsection{Bacterial cell membrane damage assay}

Damaged bacterial membrane would release cytoplasmic constituents of the cell which can be monitored easily. Release of DNA and RNA from cytoplasm can be monitored by measuring the absorbance at $260 \mathrm{~nm}$. The experiment was conducted as follows. The bacterial suspension (here E. coli) was separated into several flasks. Then ZNP, CIP and ZN-CIP of concentration $20 \mu \mathrm{g} / \mathrm{mL}$ were added in separate flasks. Samples of $1.5 \mathrm{~mL}$ were removed from the flasks every $1 \mathrm{~h}$, and immediately filtered through $0.2 \mu \mathrm{m}$ syringe filter to remove the bacteria. The supernatant was 
then diluted appropriately and optical density was recorded at $260 \mathrm{~nm}$.

\section{Characterization}

Morphology was investigated using field emission scanning electron microscope (FESEM) of Carl Zeiss (Germany) with acceleration voltage of $5.0 \mathrm{kV}$. For FESEM alcoholic dispersion of ZNP was put on a properly cleaned glass slide followed by spin coating. Ultraviolet-Visible (UV-Vis) spectra of the sample were carried out using a Shimadzu (Singapore) absorption spectrophotometer (Model No. 1700), a photoluminescence (PL) spectrum was recorded in Hitachi spectrofluorimeter (model no: F-7000). X-ray diffraction (XRD) pattern of the sample was carried out in a PANalytical X-PERT PRO (USA), applying a primary beam monochromator to select the K $\alpha 1$ component of the employed copper radiation (wavelength of $1.54056 \AA$ ). Fourier transform infrared spectroscopy (FTIR) was recorded in Perkin-Elmer (USA) spectrum 100. Prior to FTIR measurements, the samples were ground with $\mathrm{KBr}$ (spectroscopic grade) and pressed to pellets. Atomic force microscopy (AFM) was carried out using an NT-MDT (NTEGRA, Netherland). For AFM, a sample solution, diluted in ethanol, was drop casted in a properly cleaned glass slide and well dried in air. AFM was carried out in tapping mode. Particle size was determined by using transmission electron microscope (TEM) of Phillips CM 200 (Netherlands) at an operational voltage of $200 \mathrm{kV}$. For TEM micrograph, a well dispersed solution of the sample in ethanol was put into uniform carbon coated copper TEM grid and well dried in vacuum. For antibacterial efficacy OD of the samples were measured by using the same UV-Vis spectrometer with determination of minimum inhibitory concentration (MIC) and the results were analyzed statistically.

\section{Results and discussion}

\subsection{Physicochemical characterizations}

Herein we describe successful chemical conjugation of an antibiotic with ZNP and its application against drug resistant bacteria. Figure 1 shows the schematic representation of the whole process. ZNP were synthesized by a microwave assisted process from the zinc precursor, zinc acetate dihydrate, followed by its amine functionalization using 3APTES. Carboxylic acid group of the antibiotic was utilized in course of chemical conjugation with amine functionalized ZNP using EDC/NHS chemistry.

Preliminary investigation by UV-Vis spectra justified chemical conjugation of ciprofloxacin with ZNP. Figure 2

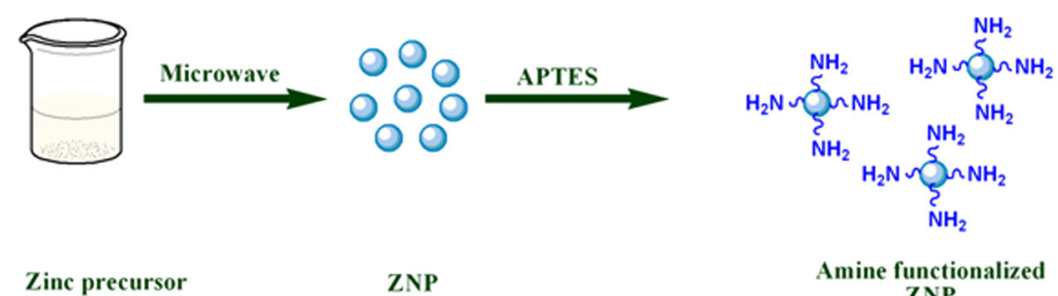

Zinc precursor $\quad$ ZNP ZNP

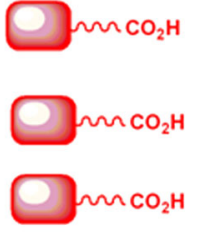

Ciprofloxacin

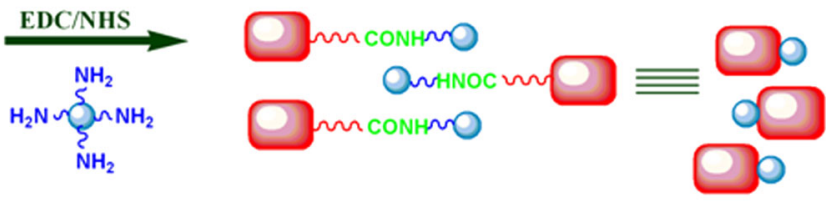

Ciprofloxacin conjugated ZNP

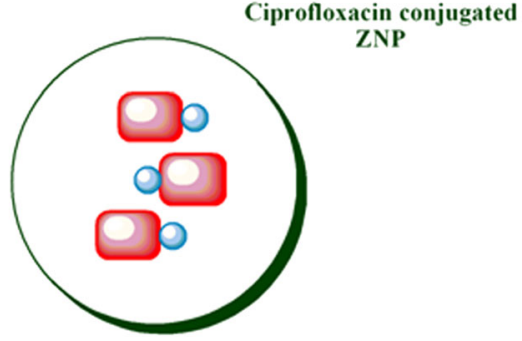

Effective against multidrug resistant bacteria

Figure 1. Schematic representation illustrating the whole process of chemical conjugation of ciprofloxacin with zinc oxide nanoparticles. 


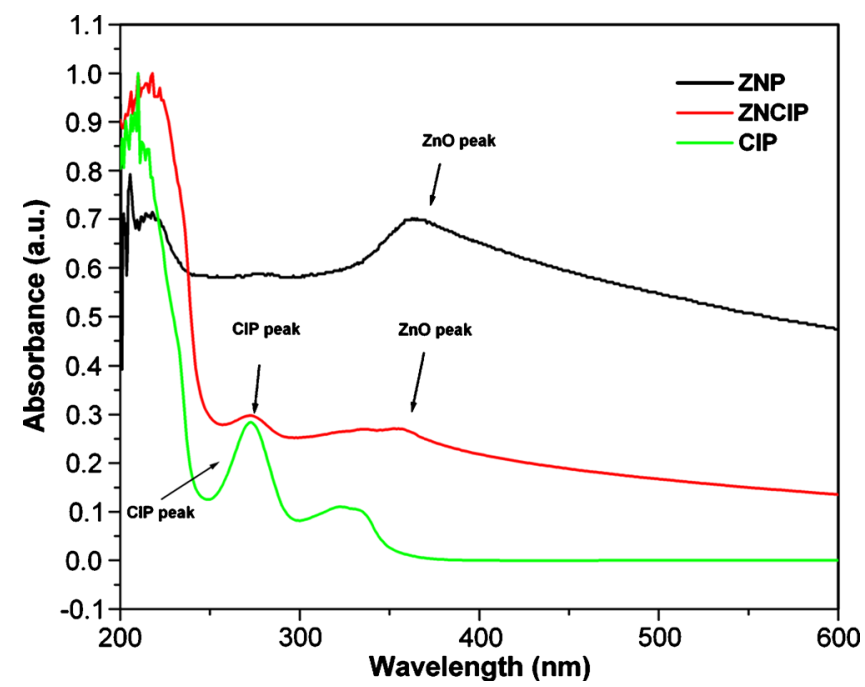

Figure 2. UV-Vis absorbance spectra of zinc oxide nanoparticles (ZNP), ciprofloxacin (CIP) and zinc oxide chemically conjugated with ciprofloxacin (ZN-CIP).

shows the UV-Vis spectra of all the three components. ZNP synthesized by microwave assisted process exhibited a steep peak at $363 \mathrm{~nm}$ and it was again a characteristic peak of ZNP (Bhattacharyya and Gedanken 2008) as reported by other processes. Meanwhile, native ciprofloxacin exhibited two characteristic peaks - one at $326 \mathrm{~nm}$ and other at $272 \mathrm{~nm}$. After conjugation with ZNP, though the second peak did not shift, the first one slightly shifted to $336 \mathrm{~nm}$ with a new peak at $357 \mathrm{~nm}$ corresponding to ZNP.

Successful conjugation was confirmed by FTIR spectra as shown in figure 3. Figure 3 (blue line) represents the FTIR spectra of ZNP in which characteristic peaks at $3400 \mathrm{~cm}^{-1}$, $1632 \mathrm{~cm}^{-1}$ and lower bands justified $\mathrm{O}-\mathrm{H}, \mathrm{C}=\mathrm{O}$ (carbonyl) and $\mathrm{Zn}-\mathrm{O}$ (Zhang et al 2010) stretching, respectively. The peaks obtained in the region of $1400 \mathrm{~cm}^{-1}$ and $1462 \mathrm{~cm}^{-1}$ were pertinent to $\mathrm{O}-\mathrm{H}$ and $\mathrm{N}-\mathrm{H}$ bending, though the amount of $\mathrm{N}-\mathrm{H}$ group was less. The red line represents FTIR spectra of amine functionalized ZNP. It shows a characteristic peak at $3373 \mathrm{~cm}^{-1}$ due to the presence of $\mathrm{O}-\mathrm{H}$ stretching frequency along with $-\mathrm{N}-\mathrm{H}$ stretching frequency of $\mathrm{NH}_{2}$ group. Peaks obtained at $2930 \mathrm{~cm}^{-1}$ were due to the asymmetric $\mathrm{C}-\mathrm{H}$ stretching frequency of the $\mathrm{CH}_{2}$ group coming from APTES fragment. Two small distinct peaks at $1580 \mathrm{~cm}^{-1}$ and $1470 \mathrm{~cm}^{-1}$ were attributed towards $\mathrm{NH}_{2}$ scissoring of primary amine. A small distinct peak at $1411 \mathrm{~cm}^{-1}$ signified $-\mathrm{O}-\mathrm{H}$ bending with a lower intensity. Two additional sharp peaks at $1020 \mathrm{~cm}^{-1}$ and $1117 \mathrm{~cm}^{-1}$ suggested $\mathrm{Si}-\mathrm{O}$ and $\mathrm{C}-\mathrm{N}$ stretching, respectively. The lower wave number band was attributed to characteristic $\mathrm{Zn}-\mathrm{O}$ stretching. The green line in figure 3 represents the FTIR spectra of ZN-CIP. Peaks obtained at $3420 \mathrm{~cm}^{-1}, 2930 \mathrm{~cm}^{-1}$ justified $\mathrm{O}-\mathrm{H}$ and $\mathrm{C}-\mathrm{H}$ stretching, respectively, whereas the amide doublet was observed at $1652 \mathrm{~cm}^{-1}$ and $1560 \mathrm{~cm}^{-1}$ (Das et al 2009). Corresponding $\mathrm{O}-\mathrm{H}$ bending was shifted to $1398 \mathrm{~cm}^{-1}$, while the other bands signifying $\mathrm{Si}-\mathrm{O}$ and $\mathrm{C}-\mathrm{N}$ stretching was

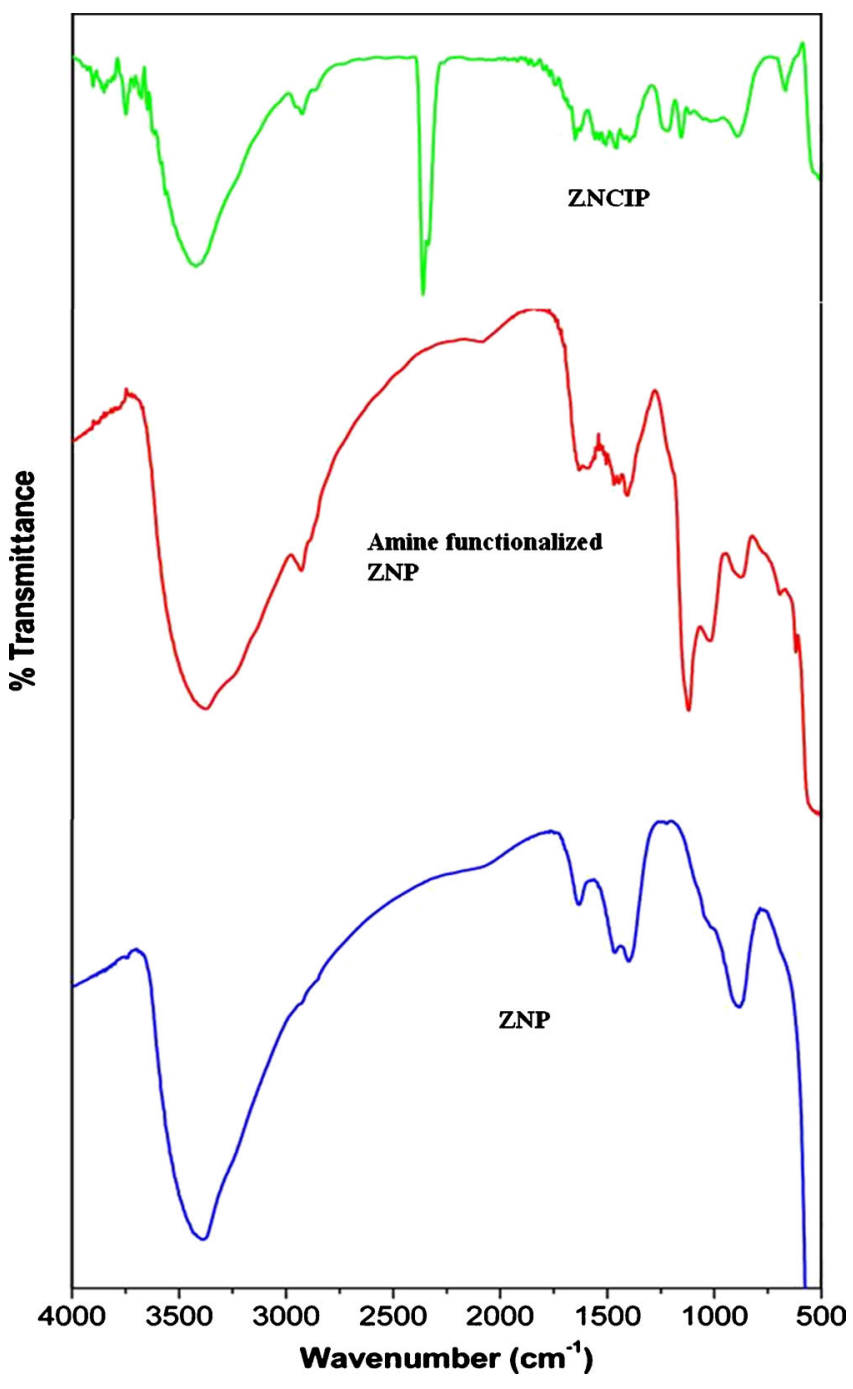

Figure 3. FTIR spectra of zinc oxide nanoparticles (blue line), amine functionalized zinc oxide nanoparticles (red line) and zinc oxide nanoparticles chemically conjugated with ciprofloxacin (green line).

shifted to $1118 \mathrm{~cm}^{-1}$ and $1229 \mathrm{~cm}^{-1}$, respectively. Small peaks obtained in the region of $1400-1550 \mathrm{~cm}^{-1}$ were similar to ciprofloxacin peaks, while $890 \mathrm{~cm}^{-1}$ signified $\mathrm{Zn}$ $\mathrm{O}$ stretching frequency and the lowest wave number band was again the characteristic peak of ciprofloxacin and $\mathrm{ZnO}$ nanoparticle, respectively.

Powder XRD of ZNP exhibited ten characteristic peaks with $2 \theta=31.60^{\circ}, 34.21^{\circ}, 36.02^{\circ}, 47.37^{\circ}, 56.51^{\circ}, 62.76^{\circ}$, $66 \cdot 15^{\circ}, 67.70^{\circ}, 68.89^{\circ}$ and $76.85^{\circ}$ which could easily be indexed to (100), (002), (101), (102), (110), (103), (200), (112), (201) and (202) diffraction planes with hexagonal structure [JCPDS card no. 034477] (Sharma et al 2010). XRD diffraction pattern is depicted in figure 4(a). No additional peaks were obtained in the diffraction pattern which suggested its chemical purity. PL property of ZN-CIP is shown in figure 4(b). Two PL peaks were obtained when it was excited at $340 \mathrm{~nm}$. The first one was the sharp one centering at $383 \mathrm{~nm}$, while the broad second one was centered 

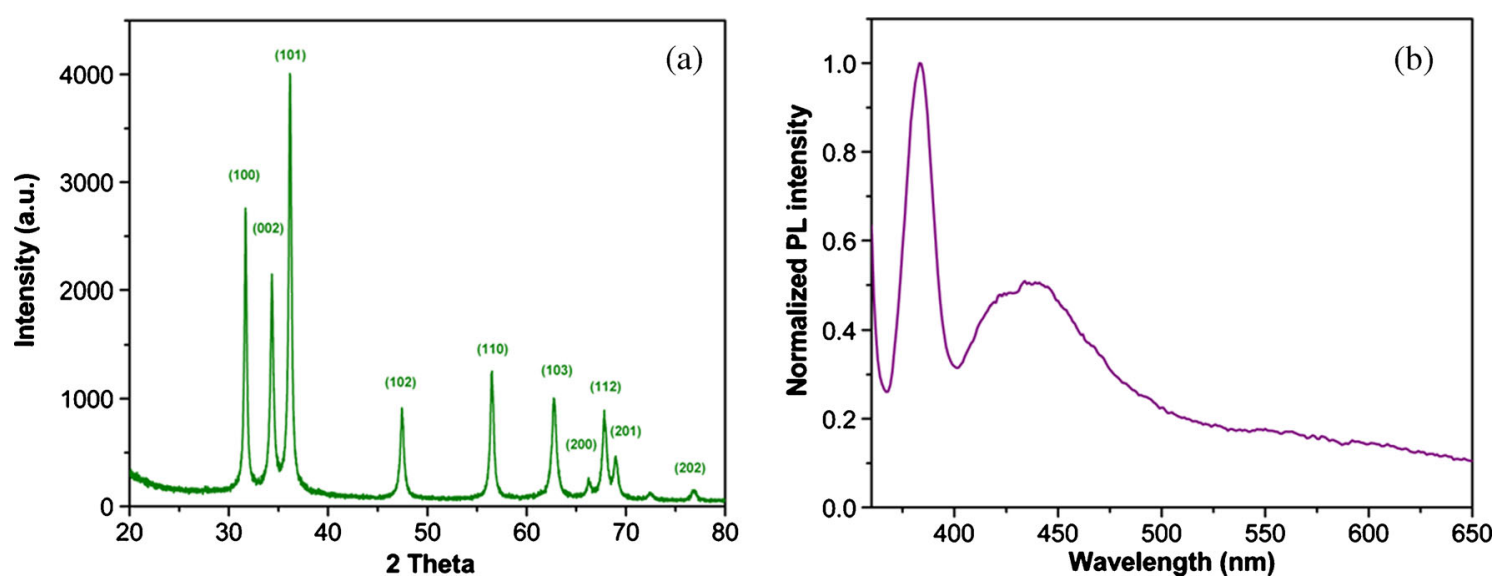

Figure 4. (a) XRD pattern of zinc oxide nanoparticles and (b) PL spectra of ciprofloxacin conjugated zinc oxide nanoparticles.
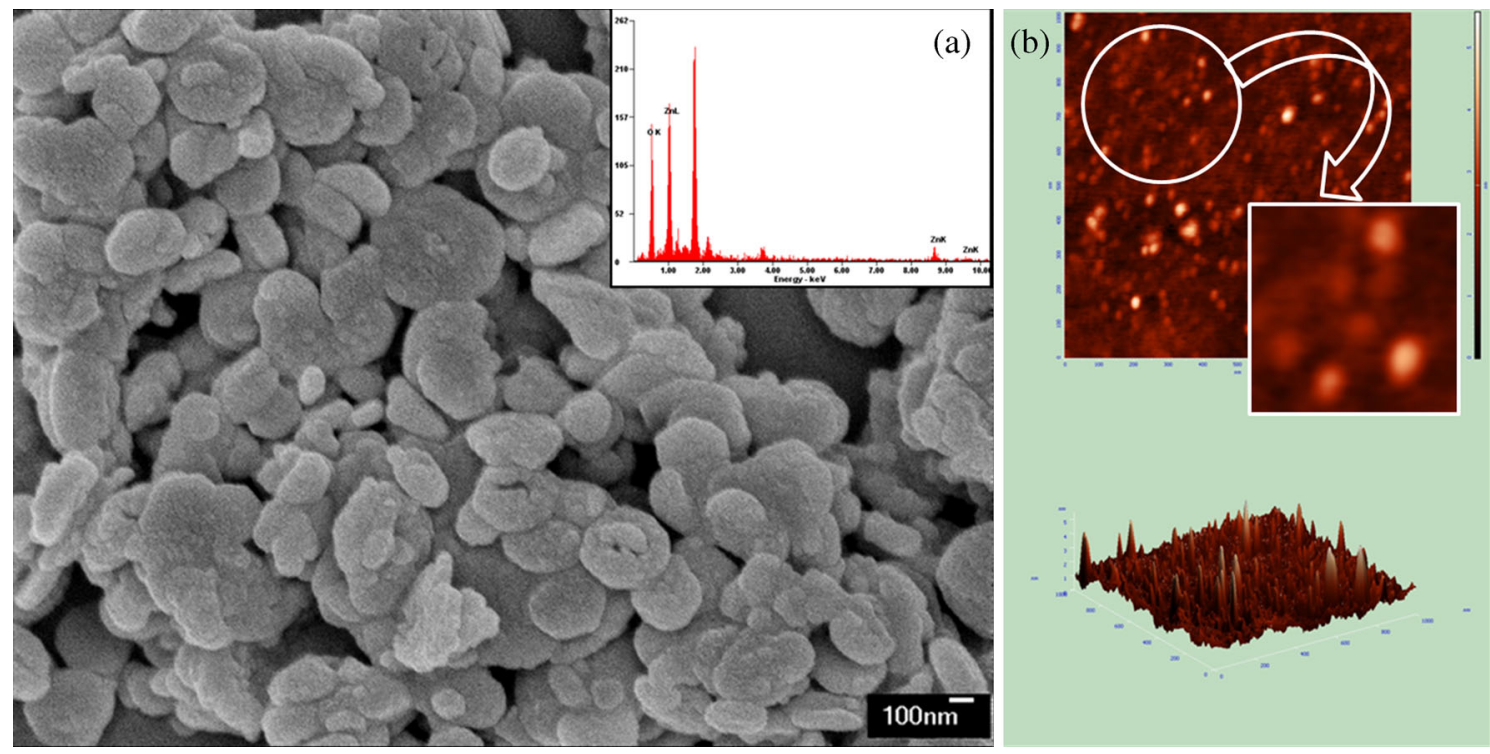

Figure 5. (a) FESEM image of ZNP and inset indicating its EDX spectrum and (b) atomic force microscopic 2D and 3D image respectively.

at $438 \mathrm{~nm}$. This pattern was identical as obtained by Pandey et al (2010), but due to chemical conjugation with ciprofloxacin the peaks were shifted to a lower wavelength. Among the bands, the lower was attributed to the recombination of excitons (Vanheusden et al 1996) while the broad peak could be indexed to singly ionized oxygen vacancy in $\mathrm{ZnO}$, resulting from the recombination of a photongenerated hole with the single ionized charge state of defect (Monticone et al 1998).

Morphology of synthesized ZNP from FESEM is shown in figure 5(a), which showed that the particles were partly spherical in nature and similar morphologies were maintained throughout. An EDX spectrum was carried out by drop casting of the sample followed by spin coating which showed $\mathrm{Zn}$ and $\mathrm{O}$ were the main chemical components. The EDX spectrum is shown in figure 5(a) inset. Zinc oxide and other semiconductor materials might be important for providing antimicrobial functionality to next generation medical devices. AFM images revealed that the particles were more or less spherical in nature. AFM image is shown in figure 5(b). AFM image also justified distribution of spherical particles.

However, the appropriate particle size was measured from HRTEM analysis which is shown in figure 6. TEM micrograph justified that the ZNP were small in size, ranging from 18 to $20 \mathrm{~nm}$, though they were agglomerated to some extent and most of them were spherical in nature. Corresponding SAED pattern is shown in figure 6 inset which 
justified its crystalline structure. This agglomeration for ZNP was expected with other TEM micrograph obtained by Bauermann et al (2006) via different synthetic route.

\subsection{Antibacterial effect of $Z N-C I P$}

Antibiotics were found to be a valuable weapon to combat bacterial infection, but their popularity had also become their undoing. Although the drugs crippled harmful microbes from within, bacteria that survived such sabotage tend to

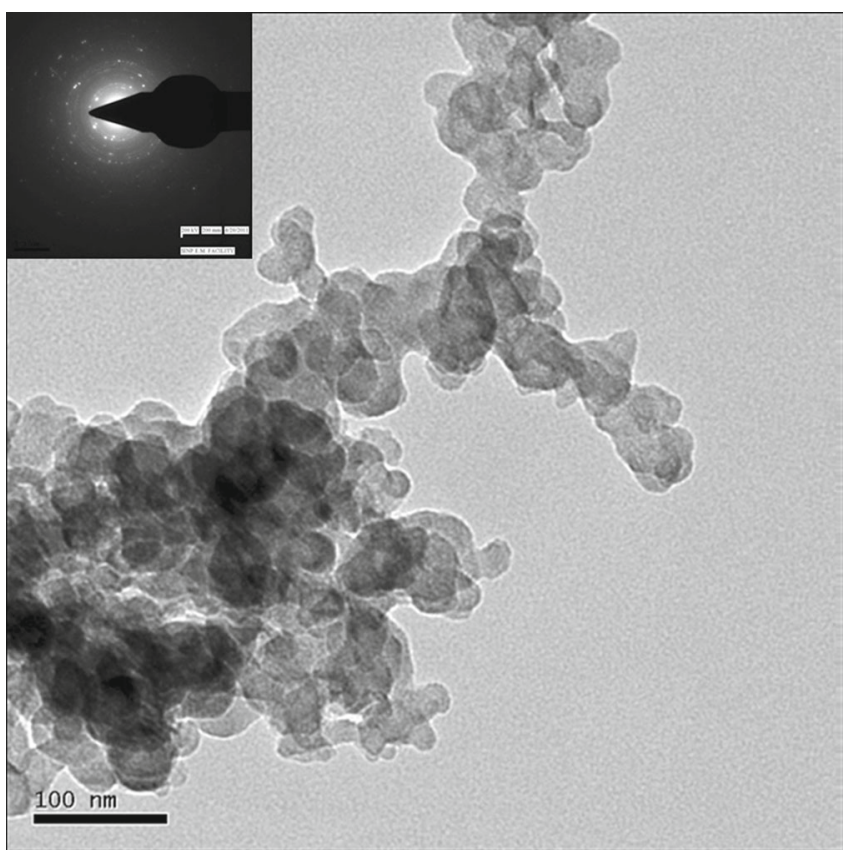

Figure 6. HRTEM image of ZNP (inset showing its SAED pattern). develop resistance that made them even more dangerous. Drug resistance developed in part because conventional antibiotics such as ciprofloxacin and doxycycline did not physically damage a microbe's cell wall. Instead, they entered their target less disruptively and moved on to disrupt the DNA within or block cell division or trigger cellular self-destruction. Strains that survived this assault, however, could evolve to defend themselves against future attacks, opened the door for deadlier versions of bacteria such as methicillin-resistant Staphylococcus aureus (MRSA), which killed nearly 19,000 Americans in 2005. To counter this, we have developed ZN-CIP to supplement pure antibiotics by destroying outer protective membranes of bacteria, ensuring that their morphing days are through.

Successful efficacy was observed by using ZN-CIP with dose dependency. Partial growths of bacterial strains were visible up to $10 \mu \mathrm{g} / \mathrm{mL}$ of $\mathrm{ZN}$-CIP concentration, but no growths were visible at $20 \mu \mathrm{g} / \mathrm{mL}$ of ZN-CIP concentration. Therefore, MIC value was found to be $20 \mu \mathrm{g} / \mathrm{mL}$ for $\mathrm{ZN}$ CIP. Meanwhile, two other antibiotics - norfloxacin and ciprofloxacin - were unable to restrict the growth of bacterial strains at similar concentration. Dose dependency bars against concentration is illustrated in figure 7. It showed that, when ciprofloxacin was conjugated with ZNP, the conjugated system was successfully able to produce an overwhelming response against multidrug resistant bacteria. Here ZNP damaged the cell membrane through reactive oxygen species (ROS) generation with free electrons and holes in presence of light (Jang et al 2006), which assisted ciprofloxacin to enter into the cell and, thereby, inhibit bacterial growth. Again ZNP were known to be abrasive due to surface defects (Stoimenov et al 2002), which could contribute to the mechanical damage of the cell membrane of bacteria to some extent as well. Even Wang et al (2007) proposed that the orientation of $\mathrm{ZnO}$

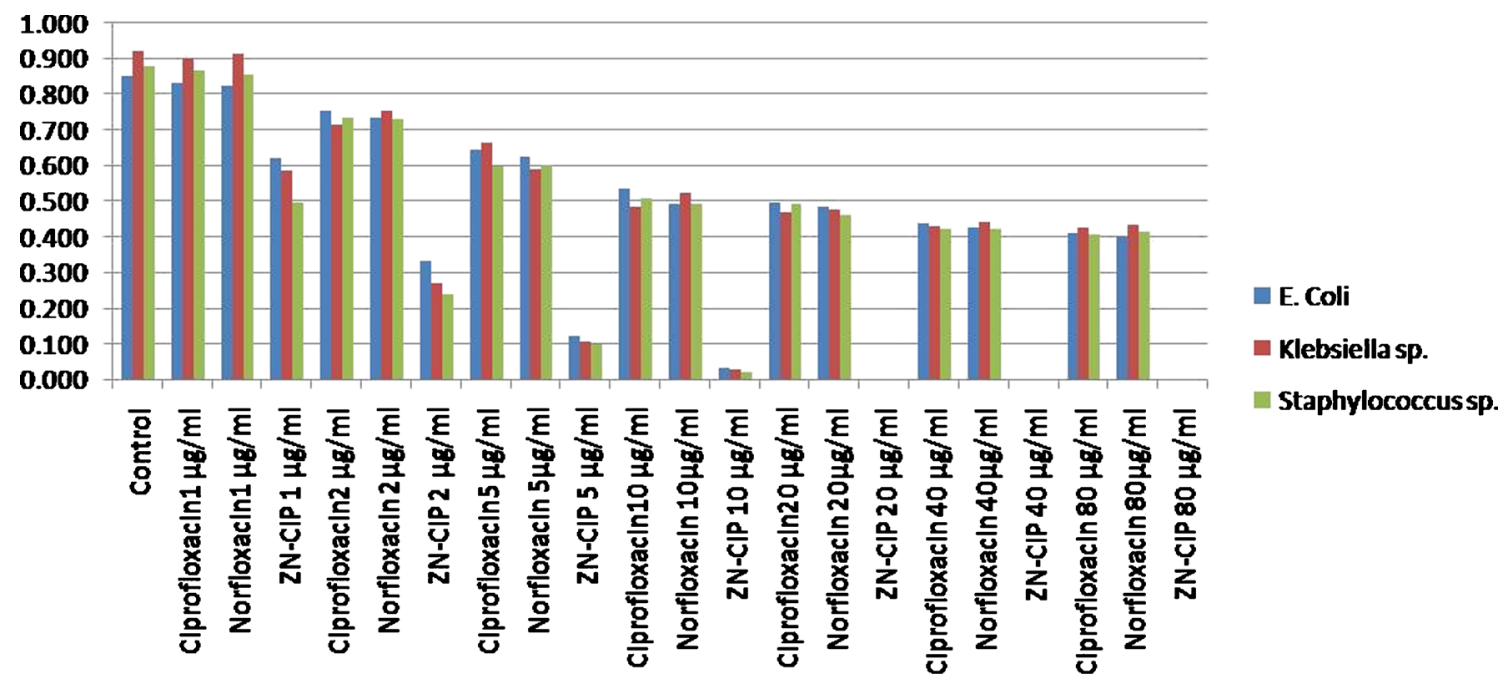

Figure 7. Estimation of MIC value of ZN-CIP against multi drug resistant clinically isolated strains of E. coli, S. aureus and Klebsiella sp. along with norfloxacin and ciprofloxacin at the concentration. 


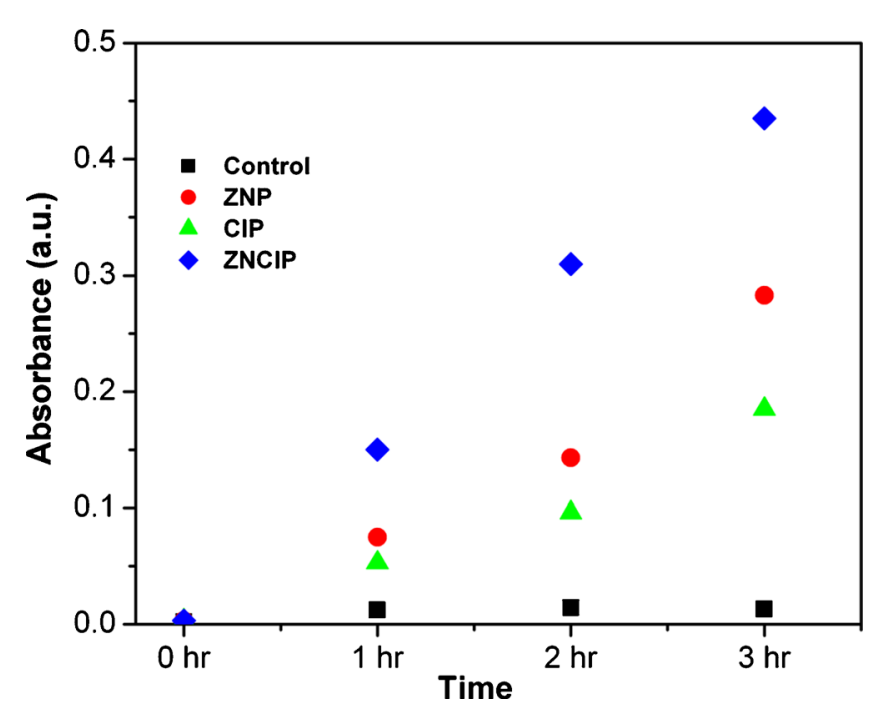

Figure 8. Mean absorbance against time to study release of cytoplasm material (DNA and RNA) from Control, ZNP, CIP and $\mathrm{ZN}-\mathrm{CIP}$ treated $E$. coli at $260 \mathrm{~nm}$ at 0, 1, 2 and $3 \mathrm{~h}$ time intervals.

can also affect outer surface of bacteria. Cell membrane damage was confirmed by $260 \mathrm{~nm}$ release assay (Chen and Cooper 2002). Release of substances such as DNA, RNA and other materials was the indicator of the integrity of the cell membrane of bacteria. Any disruption in cell membrane would lead to leakage of these substances. Hence, absorbance at $260 \mathrm{~nm}$ would increase accordingly. Figure 8 shows that the absorbance at $260 \mathrm{~nm}$ was maximum at MIC value of ZN-CIP. This could be due to the combined effect of ZNP and ciprofloxacin resulting in maximum damage of cell membrane leading to the death of bacteria in contrast to ZNP and ciprofloxacin alone.

\section{Conclusions}

In conclusion, we have reported a microwave assisted synthesis of ZNP using a buffer which is nontoxic to a wide variety of biological systems and provided an enhanced buffering capacity (Good et al 1966) under a mild reaction condition. ZNP attained hexagonal crystal structure and TEM images justified its small size distribution of 18-20 nm. ZNP were chemically conjugated with ciprofloxacin and successful chemical conjugation was confirmed by FTIR spectra. ZNCIP exhibited enhanced bactericidal activity against multi drug resistant clinically isolated strains of E. coli, S. aureus and Klebsiella sp. with dose dependency. A concentration of $10 \mu \mathrm{g} / \mathrm{mL}$ of ZN-CIP was a benchmark concentration during evaluation of MIC values. Similar concentration of antibiotic was incapable of producing antibacterial activity. The roughness of native ZNP of ZN-CIP, together with ROS, damaged the bacterial cell membrane allowing the antibiotic conjugated ZN-CIP to penetrate into the cell and disrupt cell division which is not possible with the antibiotic alone.

\section{Acknowledgement}

The authors would like to thank DBT-GOI, ICAR-NAIP, ICAR-National Fund, and ISI Plan Project 2011-2014 for their generous financial support. SM is thankful to CSIR for their financial assistance.

\section{References}

Applerot B G, Lipovsk A, Dror R, Perkas N, Nitzan Y, Lubart R and Gedanken A 2009 Adv. Funct. Mater. 19842

Banoee M, Seif S, Nazari Z E, Fesharaki P J, Shahverdi H R, Moballegh A, Moghaddam K M and Shahverdi A R $2010 \mathrm{~J}$. Biomed. Mater. Res. B 93B 557

Bauermann L P, Bill J and Aldinger F 2006 J. Phys. Chem. B 110 5182

BBC News 1 June 2011 (http://www.bbc.co.uk/news/worldeurope-13613487)

Bhattacharyya S and Gedanken A 2008 Micropor. Mesopor. Mat. 110553

Blanc D S, Banuls A L, Hauser P M, Moreillon P, Francioli P and Tibayrenc M 2000 Microb. Drug Resist. 6231

Chakraborty S P, Sahu S K, Mahapatra S K, Santra S, Bal M, Roy S and Pramanik P 2010 Nanotechnology 21105103

Chen C Z and Cooper S L 2002 Biomater. 233359

Chivukula V, Ciplys D, Shur M and Dutta P 2010 Appl. Phys. Lett. 96233512

Das M, Mishra D, Dhak P, Gupta S, Maity T K, Basak A and Pramanik P 2009 Small 242883

Dutta R K, Sharma P K, Bhargava R, Kumar N and Pandey A C 2010 J. Phys. Chem. B 1145594

Good N E, Winget G D, Winter W, Connolly T N, Izawa S and Singh R M M 1966 Biochemistry 5467

Guo Y, Wang H, He C, Qiu L and Cao X 2009 Langmuir 254678

Jang Y J, Simer C and Ohm T 2006 Mater. Res. Bull. 4167

Ku C H and Wu J J 2007 Nanotechnology 18505706

Lee Y J, Ruby D S, Peters D W, McKenzie B B and Hsu J W P 2008 Nano Lett. 81501

Li S F, Zhang X M, Du W X, Ni Y H and Wei X W 2009 J. Phys. Chem. C 1131046

Mitra S, Chandra S, Laha D, Patra P, Debnath N, Pramanik A, Pramanik P and Goswami A 2012 Mater. Res. Bull. 47586

Monticone S, Tufeu V and Kanaev A V 1998 J. Phys. Chem. B 102 2854

Padmavathy N and Vijayaraghavan R 2008 Sci. Technol. Adv. Mater. 9035004

Pandey A C, Sanjay S S and Yadav R S 2010 J. Exp. Nanoscience 5488

Reddy K M, Feris K, Bell J, Wingett D G, Hanley C and Punnoose A 2007 Appl. Phys. Lett. 90213902

Ren X, Chen D, Meng X, Tang F, Hou X, Han D and Zhang L 2009 J. Colloid Interface Sci. 334183

Saha B, Bhattacharya J, Mukherjee A, Ghosh A K, Santra C R, Dasgupta A K and Karmakar P 2007 Nanoscale Res. Lett. 2 614

Sharma D, Rajput J, Kaith B S, Kaur M and Sharma S 2010 Thin Solid Films $\mathbf{5 1 9} 1224$

Stoimenov P K, Klinger R L, Marchin G L and Klabunde K J 2002 Langmuir 186679 
Turos E, Shim J Y, Greenhalgh K, Reddy G S, Dickey S and Lim D V 2007 Bioorg. Med. Chem. Lett. 1753

Vanheusden K, Warren V, Seager C H, Tallant D R, Voigt J A and Gnade B E 1996 J. Appl. Phys. 797983

Wang X, Yang F, Yang W and Yang X 2007 Chem. Commun. 42 4414
Wang Z L 2004 Materials Today 726

Wang Z L and Song J H 2006 Science 312242

Yude W, Shuo Z, Xinghui W and Qingju L 2006 Mater. Chem. Phys. 98121

Zhang B, Kong T, Xu W, Su R, Gao Y and Cheng G 2010 Langmuir 264514 